УДК 331.45:368.2.025.731

ПРИМЕНЯЕМЫЕ ВИДЫ ПОДГОТОВКИ ЛИЧНОГО СОСТАВА

ГАЗОДЫМОЗАЩИТНОЙ СЛУЖБЫ В НЕПРИГОДНОЙ ДЛЯ ДЫХАНИЯ СРЕДЕ

\title{
APPLIED TYPES OF PERSONAL PREPARATION OF THE GAS-PROTECTIVE SERVICE IN UNSUITABLE FOR BREATHABLE ENVIRONMENT
}

\author{
Е.И. Стабровская, Н.Н. Турова, Н.В. Васильченко, \\ М.В. Просин, М.Н. Чалаташвили
}

Кемеровский государственный университет, г. Кемерово, Российская Федерация

Elena I. Stabrovskaya, Natalia N. Turova, Natalia V. Vasilchenko, Maxim V. Prosin, Malkhaz N. Chalatashvili

Kemerovo State University, Kemerovo, Russian Federation

e-mail: helist@inbox.ru

Аннотация. В работе рассмотрены вопросы подготовки личного состава газодымозащитной службы как вида деятельности, обеспечивающего получение и совершенствование профессиональных знаний, практических умений и навыков, необходимых для выполнения служебных обязанностей в сфере газодымозащитной службы. Несмотря на то, что на сегодняшний день газодымозащитная служба является одной из главных в комплексе специальных служб пожарной охраны, перед ней еще стоит много не разрешенных проблем. Условия, отягощающие протекание пожаров, требуют новых видов подготовки газодымозащитной службы, овладение спасателями новыми техниками дыхания, способами самоспасания, 
систематического проведения тренировок в условиях, приближенных к реальным.

Рассмотренные методики относятся к современным способам подготовки газодымозащитников, которые позволят сохранить жизни пожарных и людей, спасти пострадавших в аварийных ситуациях любой сложности, обеспечить безопасность и свести к минимуму вредное и опасное воздействие факторов пожара на человека.

Abstract. The paper considers the issues of training the personnel of the gas and smoke protection service as a type of activity that ensures the acquisition and improvement of professional knowledge, practical skills and abilities necessary to perform official duties in the field of gas and smoke protection service. Despite the fact that today the gas and smoke protection service is one of the main in the complex of special fire services, it still faces many unresolved problems. The conditions that aggravate the course of fires require new types of training for the gas and smoke protection service, the mastery of new breathing techniques, methods of self-rescue by rescuers, and systematic training in conditions close to real ones.

The considered methods relate to modern methods of training gas and smoke defenders, which will save the lives of firefighters and people, save victims in emergency situations of any complexity, ensure safety and minimize the harmful and dangerous effects of fire factors on a person.

Ключевые слова: пожар; газодымозащитная служба; дыхательный аппарат; аварийно-спасательные работы; кислород; дыхательная техника; непригодная для дыхания среда

Keywords: fire; gas and smoke protection service; breathe-helping machine; rescue operations; oxygen; breathing technique; unbreathable environment 


\section{Введение}

Инфраструктура современных городов и населенных пунктов становится насыщенной пожарной нагрузкой, представляющей особою опасность для людей и участников тушения пожара. Строящиеся здания обладают большой протяженностью и объемами помещений, сообщенной планировкой и нестандартными решениями при создании путей движения людей внутри здания.

Временная пожарная нагрузка и элементы отделки помещения, выполнены из синтетических материалов, которые при горении выделяют отравляющие вещества. Кроме этого, эти материалы обладают высокой дымообразующей способностью. Все вышеперечисленное создает опасную и непредсказуемую обстановку на пожаре, способствующую гибели не только мирного населения, но и самих пожарных.

Примеры характерных пожаров:

- 23 сентября 2016 г., г. Москва. Крупный пожар на складе недалеко от станции метро «Черкизовская». Погибли 8 пожарных;

- 30 мая 2019 г., г. Набережные Челны. Пожар на пустыре на Автосборочном проспекте. Погиб командир отделения пожарноспасательной части № 54;

- 28 февраля 2018 г., г. Москва. Пожар в квартире на бульваре Матроса Железняка. Погибли 2 пожарных.

Эти цифры заставляют задуматься о создании и применении нoвblх направлений в подготовке газодылмзащчитников, одним из которых является выживание звена газодымозащитной службы (ГДЗС), или одного газодымозащитная в случаях потери ориентации, обрушении, взрыва и других аварийных случаев. 


\section{Теоретические основы}

На сегодняшний день газодымозащитная служба -одна из главных составляющих в комплексе пожарной охраны, перед ней стоит немало проблем, основные из которых изложены в Концепции развития ГДЗС в системе Государственной противопожарной службы.

Основными путями решения, а также приоритетными направлениями развития являются:

- изменение нормативной базы;

- повышение эффективности организации деятельности ГДЗС;

- внедрение новых видов средств индивидуальной защиты органов дыхания (СИЗОД) с улучшенными тактико-техническими характеристиками;

- создание и развитие материально-технической базы ГДЗС;

- улучшение системы подготовки газодымозащитников;

- предложение и развитие новых методик к самовыживанию и проведению аварийной разведки и спасению пожарного (АРиСП);

- повышение эффективности организации боевых действий по тушению пожаров с использованием СИЗОД;

- совершенствование управленческой и контрольной деятельности;

- создание безопасных условий труда пожарных.

Для дальнейшего развития ГДЗС необходимо еще немало усилий, поэтому решение этих проблем является на сегодняшний день основной задачей в организации газодымозащитной службы [1].

Подготовка личного состава газодымозащитной службы - вид деятельности, обеспечивающий получение и совершенствование профессиональных знаний, практических умений и навыков, необходимых для выполнения служебных обязанностей в сфере ГДЗС [2].

Подготовка газодымозащитников к работе в непригодной для дыхания среде (НДС) при аварийной ситуации включает в себя: 
- совершенствование физической, медицинской, психологической, специальной, подготовки;

- совершенствование умений содержать в полной технической исправности СИЗОД, другое закрепленное за ним пожарно-техническое вооружение, обеспечивать в установленные сроки их эксплуатацию и обслуживание;

- совершенствование умений проводить расчеты запаса воздуха и времени работы звена ГДЗС в СИЗОД в соответствии с Методикой проведения расчетов параметров работы в СИЗОД;

- совершенствование умений выполнять требования Порядка тушения пожаров, Правил охраны труда в подразделениях;

- совершенствование умений оказывать первую помощь пострадавшим на пожаре;

- совершенствование навыков действий в составе звена (отделения) ГДЗС при ведении аварийно-спасательных работ (АСР) по тушению пожаров [3, 4].

В последнее время кардинально изменились условия работы газодымозащитников. При проведении АСР, а также при тушении пожаров с использованием средств индивидуальной защиты органов дыхания и зрения в непригодной для дыхания среде характерными опасными и вредными факторами, воздействующими на пожарных, являются высокая концентрация дыма, ядовитые газы, пониженная концентрация кислорода, критические температуры в помещении, психическая напряженность $[2,5,6]$.

Современные условия, отягощающие протекание пожаров, требуют новых видов подготовки ГДЗС (психологических), овладение спасателями новыми техниками дыхания, способами самоспасания, систематического проведения тренировок в условиях, приближенных к реальным.

Газодымозащитники подвергаются не только высокому уровню физических нагрузок, но и воздействию нервно-психического напряжения. 
В специальной защитной одежде и снаряжении они поднимаются на верхние этажи зданий по штурмовой и выдвижной лестницам. Работают они в ограниченном пространстве, под воздействием мощных тепловых потоков, открытого пламени и искр, а это соответственно может привести к ожогам кожного покрова и органов дыхания [7].

Это свидетельствует о необходимости введения в профессиональную подготовку газодымозащитников специальных периодических тренировок (физических) и специальных видов подготовки, обеспечивающих решение поставленных задач в современных изменяющихся условиях.

Одной из таких тренировок является техника дыхания 10 атм, которая позволит улучшить физические и профессионально-технические показатели газодымозащитника, a, следовательно, повысить их способность к выживанию в аварийных ситуациях.

Каждого пожарного беспокоит мысль о том, что он может остаться в непригодной для дыхания среде с относительно малым количеством воздуха. Газодымозащитники, которые работают на пожарах, знают, что баллона объемом 7 л с давлением 300 атм является достаточным на 30 мин работы. Остатка в 60 атм хватает на 5-7 мин. При срабатывании звукового сигнала пожарные переходят в состояние сильного стресса, который вызван смертельной опасностью, руководствуясь малым количеством времени для работы в непригодной для дыхания среде $[1,4]$. На самом деле остатка в 55 атм может быть достаточно не на 5 мин, а на большее количество времени даже простому человеку, который прошел специальную подготовку.

Специальная подготовка необходима для тренировки «суперспособности» растягивать запас воздуха, она включает в себя упражнение - «10 очков».

Упражнение «10 очков» используется для обучения и совершенствования навыков дыхания в дыхательных аппаратах на сжатом воздухе. Оно учит газодымозащитников увеличивать защитное время действия дыхательного аппарата в 3-6 раз с помощью сокращения 
двигательной и мыслительной активности и использования особых дыхательных техник.

Во время работы в непригодной для дыхания среде могут возникать ситуации, требующие по максимуму снизить расход воздуха, например:

- ожидание своей очереди на преодоление препятствия при движении в звене;

- выполнение сложной работы по очереди;

- ожидание помощи при возможной потере ориентации или ситуации, когда пути выхода перекрыты.

Именно в таких случаях необходима «суперспособность», чтобы иметь возможность дышать в несколько раз дольше, чем обычно при ограниченном запасе воздуха. Возможность дышать при остаточном давлении воздуха 50-60 атм в баллоне емкостью 7 л в течение 35-60 мин обеспечивает достаточное время для того, чтобы найти и спасти пострадавшего или аварийного газодымозащитника.

Методика обучения «суперспособности» разработана, проверена и успешно внедрена в пожарно-спасательные подразделения. Она основывается на двух методах: применении специальных дыхательных техник и ограничение двигательной и мыслительной активности («снижение нагрузки»).

Ограничение двигательной и мыслительной активности («снижение нагрузки»). Газодымозащитник, который включен в дыхательный аппарат со сжатым воздухом (ДАСВ), ложится на горизонтальную поверхность, расслабляет лицевые мышцы и мышцы тела.

Для поддержания активной работы мозга требуется большое количество кислорода. Чтобы обеспечить организму покой, необходимо уменьшить мыслительную нагрузку. Это достигается по средствам закрытия глаз и исключения ненужных мыслей. Также эффективно пребывание в оптимистичном эмоциональном состоянии для снижения уровня стресса, 
потому что стресс губителен для организма, выражается в повышении потребления кислорода.

Использование метода «снижение нагрузки» позволяет дышать запасом воздуха в 10 атм с баллоном 7 л на протяжении 6-8 мин или продержаться на запасе воздуха в 55 атм в течение 45 мин.

Обеспечение подачи кислорода ниже постоянного расхода ДАСК может быть осуществлено с помощью периодического закрывания вентиля кислородного баллона, однако данный способ представляет опасность в силу возможной потери сознания при перекрытом вентиле, что может, в свою очередь, привести к смертельному исходу в результате гипоксии. Поэтому ограничение активности - единственный метод снижения расхода кислорода, при работе в дыхательных аппаратах на сжатом кислороде (ДАСК).

Дьхательные техники. Дыхательные техники используются для того, чтобы максимально извлечь и усвоить кислород организмом из воздушной смеси, которая вдыхается пользователем из дыхательного аппарата, при этом содержание кислорода в выдыхаемом воздухе уменышается с обычных 16-18 \% до 10-13\%. В атмосферном воздухе и в баллоне дыхательного аппарата содержится 20,9 \% об. кислорода. Выходит, что при обычном дыхании человек получает воздух с 21 \%, а выдыхает с 17 \% кислорода, таким образом, усваиваются только 4 \% кислорода из 21 \%. При увеличении нагрузки расход воздуха также увеличивается, однако количество усвоенного кислорода уменьшается. Это происходит, потому что при быстром дыхании вдыхаемый воздух присутствует в легких меньшее время, и кровь через легочные альвеолы успевает извлечь из воздуха кислорода меньшее количество. Когда организм испытывает тяжелые нагрузки, он нуждается в кислороде больше, но при этом извлекает из воздуха долю кислорода меньшую и организму приходится компенсировать снижение эффективности извлечения кислорода с помощью увеличения частоты 
дыхания, что опять приводит к снижению эффективности извлечения кислорода.

Поэтому качественные тренировки силовой выносливости и скорости должны привести к увеличению объема вдоха, повышению кислородной емкости крови и значительному снижению частоты дыхания под нагрузкой. Повышение способности организма к извлечению кислорода из воздуха это и есть цель тренировок выносливости. Если время выполнения работы превышает анаэробное время, то объем работы организма полностью ограничен количеством извлеченного при дыхании кислорода.

В то же время, если увеличить извлечение кислорода, чтобы в выдохе было $13 \%$ кислорода вместо 17 \%, то организм будет усваивать не 4 процентных пункта, а 8. Таким образом, он получит возможность выполнять в 2 раза больший объем работы или продержится на том же запасе воздуха в 2 раза дольше.

Метод увеличения времени защитты методом применения дыхательных техник. С теоретической точки зрения увеличить количество извлекаемого кислорода из вдоха возможно с помощью задержки дыхания после вдоха. Однако данный способ малоэффективен по той причине, что потребность в выдохе появляется достаточно быстро. Поэтому нужно научиться обманывать чувство необходимости во вдохе, что соответственно позволит увеличить время дыхания. Для этого необходимо осуществлять короткие и маленькие по объему вдохи. Эти вдохи будут пережаты паузами и после сделанного малого вдоха, на короткое время желание дышать уменьшится. В том случае, если увеличится желание дышать, необходимо вновь осуществить малый вдох с паузами до наполнения легких. Можно на высоте вдоха сделать большую паузу, тогда желание выдохнуть при полном вдохе развивается медленнее. Это связано с тем, что объем воздуха в легких достиг своего максимума, и при той же скорости потребления, концентрация кислорода в легких снижается медленнее, чем при полу- 
вдохе. В случае, когда появляется желание выдохнуть, при выдохе также необходимо делать маленькими порциями с паузами между ними.

Как показывает опыт, при длительной задержке дыхания быстрый выдох не снижает желание выдохнуть и вдохнуть. После незначительного выдоха наоборот желание дышать на определенное количество времени очень сильно уменьшается. Благодаря такому эффекту время выдоха можно увеличить до 40 с и более. Кислород на протяжении всего времени из легких продолжает всасываться в кровь, так что его содержание может снизиться в конце выхода на $10 \%$.

Содержание в крови углекислого газа стимулирует желание осуществлять вдох и выдох и автоматическое дыхание. Следовательно, при выдохе необходимо как можно сильнее выдохнуть, и тогда останется меньше в легких старого воздуха, то, соответственно, и останется меньше углекислого газа. И в этом случае делать дыхательные паузы будет легче. Чтобы не допустить чувство удушья, необходимо делать больше маленьких вдохов с минимальными паузами и маленьких выдохов. Если нарушить правила метода, то тогда можно спровоцировать некоторый дефицит дыхания. Тогда следует промыть легкие воздухом. Нет необходимости при этом делать вдох посреди выдоха: к сожалению особого облегчения не наступит, так как углекислый газ останется в легких. Промывку легких необходимо делать после осуществления полного выдоха, делая при этом увеличенные дробные вдохи с меньшими, чем обычно, паузами, до полного вдоха и немного уменьшая паузу на высоте вдоха. Чтобы восстановить дыхание по данной методике достаточно одного промывочного вдоха, выдох получается уже обычным. В результате проведения многочисленных тренировок, человек адаптируется к методике дыхания и длительность дыхания на запасе 10 атм может достигать до 8,5-9,0 мин (5 ч дыхания на 1 баллон). 


\section{Выводы}

Пожары как социально-экономическое явление нередко приводят к невосполнимым потерям, унося человеческие жизни. Следует усвоить, что современные пожары стали наиболее опасными в сравнении с теми, которые наблюдались много лет назад, что обуславливает необходимость внедрения новых средств и способов подготовки пожарных для обеспечения пожарной безопасности.

Из-за чего же все-таки современные пожары стали более опасными и почему это произошло? Ответить на этот вопрос можно следующим образом: синтетическая горючая нагрузка, а конструкции стали легковозводимыми.

При внутренней отделке помещений использовалось в основе дерево и другие природные материалы. Мебель, предметы обихода и декора, строительные материалы - все это в основном изготовлялось из материалов природного происхождения. Сегодня стоит зайти в любое помещение жилое или общественное - и видна совершенно другая картина. Предметы интерьера и бытовая техника производятся из пластмассы, напольные покрытия синтетические, мебель тоже делается из синтетических материалов и синтетическими материалами набивается.

Проблема использования синтетических материалов заключается в том, что в сравнении с деревянными изделиями они горят быстрее, выделяют больше тепла, густого едкого дыма и большое количество очень токсичных продуктов горения.

При горении современной квартиры пожарные имеют дело с эквивалентом горения бензина, а не горением дерева, как это было много лет назад. По этим причинам современный пожар распространяется быстрее и при этом наносит намного больше ущерба.

Густой черный дым, который выделяется при горении современных синтетических материалов, серьезно ухудшает видимость, что делает разведку более сложной и опасной. Именно по этой причине следует 
тренироваться только в условиях нулевой видимости. Кроме этого, проблемой, усложняющую обстановку на пожаре, стали температурные выбросы и повторные воспламенения дыма.

Вторая причина того, что пожары стали опаснее, - легковозводимые конструкции. При строительстве большинства современных зданий применяются балки (как металлические, так и деревянные), продукты деревопереработки, синтетические клеи и композитные материалы. Данные конструкции обрушаются даже при незначительном огневом воздействии, заблаговременно не подавая признаков обрушения. Как перекрытия между этажами, так и кровля при наличии балок очень опасны для нахождения пожарных на них во время пожара, особенно это касается кровли.

Рассмотренные методики относятся к современным способам подготовки газодымозащитников, которые позволят сохранить жизни пожарных и людей, спасти пострадавших в аварийных ситуациях любой сложности, обеспечить безопасность и свести к минимуму вредное и опасное воздействие факторов пожара на человека.

\section{Список используемых источников}

1. Волков О.Г., Апарин А.А., Захаров Д.Ю., Бочкарев А.Н. Концепция работы звена ГДЗС на основе инновационных технологий // Проблемы обеспечения безопасности при ликвидации последствий чрезвычайных ситуаций. 2015. Т. 2. № 1 (4). С. 12-16.

2. Грачев В.А., Теребнев В.В., Поповский Д.В. Газодымозащитная служба. М.: Калан, 2012. 280 с.

3. Карпов А.В., Карпова А.А. Понятие профессионально важных качеств деятельности. М.: ВЛАДОС-пресс, 2003. 352 с.

4. Легошин М.Ю., Чистяков И.М., Шипилов Р.М., Никишов С.Н. Совершенствование профессионального уровня подготовки газодымозащитников в ФГБОУ ВО Ивановская пожарно-спасательная академия ГПС МЧС России // Пожарная и аварийная безопасность: матер. 
XI международ. науч.-практ. конф., посвященной Году пожарной охраны. Иваново: Ивановская пожарно-спасательная академия ГПС МЧС России, 2016. C. 267-269.

5. Елькин А.Б., Тишков К.Н. Управление безопасностью труда. Нижний Новгород: Нижегород. гос. техн. ун-т им. Р.Е. Алексеева, 2008. 105 с.

6. Кабелев Н.А. Пожарная разведка: тактика, стратегия и культура. Екатеринбург: Калан, 2016. 348 с.

7. Шленков А.В. Психологическое обеспечение профессиональной подготовки сотрудников Государственной противопожарной службы МЧС России: концепция, принципы, технологии: дис. ... д-ра псих. наук. СПб., 2010. 394 c.

\section{References}

1. Volkov O.G., Aparin A.A., Zakharov D.Yu., Bochkarev A.N. Kontseptsiya raboty zvena GDZS na osnove innovatsionnykh tekhnologii [The Concept of the GDZS Unit Operation Based on Innovative Technologies]. Problemy obespecheniya bezopasnosti pri likvidatsii posledstvii chrezvychainykh situatsii Safety Issues in Disaster Management, 2015, Vol. 2, No. 1 (4), pp. 12-16. [in Russian].

2. Grachev V.A., Terebnev V.V., Popovskii D.V. Gazodymozashchitnaya sluzhba [Gas and Smoke Protection Service]. Moscow, Kalan Publ., 2012. 280 p. [in Russian].

3. Karpov A.V., Karpova A.A. Ponyatie professional'no vazhnykh kachestv deyatel'nosti [The Concept of Professionally Important Qualities of Activity]. Moscow, VLADOS-press Publ., 2003. 352 p. [in Russian].

4. Legoshin M.Yu., Chistyakov I.M., Shipilov R.M., Nikishov S.N. Sovershenstvovanie professional'nogo urovnya podgotovki gazodymozashchitnikov v FGBOU VO Ivanovskaya pozharno-spasatel'naya akademiya GPS MChS Rossii [Improvement of Professional Level of Preparation of Vasodilatation in of the Ivanovo Fire and Rescue Academy of State Fire 
Service of EMERCOM of Russia]. Materialy XI Mezhdunarodnoi nauchnoprakticheskoi konferentsii, posvyashchennoi Godu pozharnoi okhrany «Pozharnaya $i$ avariinaya bezopasnost'» [Materials of the XI International Scientific and Practical Conference Dedicated to the Year of Fire Protection «Fire and Emergency Safety»]. Ivanovo, Ivanovskaya pozharno-spasatel'naya akademiya GPS MChS Rossii Publ., 2016, pp. 267-269. [in Russian].

5. Elkin A.B., Tishkov K.N. Upravlenie bezopasnost'yu truda [Occupational Safety Management]. Nizhny Novgorod, Nizhegorod. gos. tekhn. un-t im. R.E. Alekseeva Publ., 2008. 105 p. [in Russian].

6. Kabelev N.A. Pozharnaya razvedka: taktika, strategiya i kul'tura [Fire Intelligence: Tactics, Strategy and Culture]. Yekaterinburg, Kalan Publ., 2016. 348 p. [in Russian].

7. Shlenkov A.V. Psikhologicheskoe obespechenie professional'noi podgotovki sotrudnikov Gosudarstvennoi protivopozharnoi sluzhby MChS Rossii: kontseptsiya, printsipy, tekhnologii: dis. d-ra psikh. nauk [Psychological Support of Professional Training of Employees of the State Fire Service of the EMERCOM of Russia: Concept, Principles, Technologies: Doct. Psych. Sci. Diss.]. St. Petersburg, 2010. 394 p. [in Russian].

\section{Сведения об авторах}

\section{About the authors}

Стабровская Елена Игоревна, канд. техн. наук, доцент кафедры «Техносферная безопасность», Кемеровский государственный университет, г. Кемерово, Российская Федерация

Elena I. Stabrovskaya, Candidate of Engineering Sciences, Assistant Professor of Technosphere Safety Department, Kemerovo State University, Kemerovo, Russian Federation

e-mail: helist@inbox.ru 
Турова Наталья Николаевна, канд. техн. наук, доцент кафедры «Техносферная безопасность», Кемеровский государственный университет, г. Кемерово, Российская Федерация

Natalia N. Turova, Candidate of Engineering Sciences, Assistant Professor of Technosphere Safety Department, Kemerovo State University, Kemerovo, Russian Federation

e-mail: natalya_turova@inbox.ru

Васильченко Наталья Викторовна, канд. техн. наук, доцент кафедры «Техносферная безопасность», Кемеровский государственный университет, г. Кемерово, Российская Федерация

Natalia V. Vasilchenko, Candidate of Engineering Sciences, Assistant Professor of Technosphere Safety Department, Kemerovo State University, Kemerovo, Russian Federation

e-mail: natalivasi@yandex.ru

Просин Максим Валерьевич, канд. техн. наук, доцент кафедры «Техносферная безопасность», Кемеровский государственный университет, г. Кемерово, Российская Федерация

Maxim V. Prosin, Candidate of Engineering Sciences, Assistant Professor of Technosphere Safety Department, Kemerovo State University, Kemerovo, Russian Federation

e-mail: prosinmv@yandex.ru

Чалаташвили Малхаз Николаевич, канд. техн. наук, доцент кафедры «Техносферная безопасность», Кемеровский государственный университет, г. Кемерово, Российская Федерация

Malkhaz N. Chalatashvili, Candidate of Engineering Sciences, Assistant Professor of Technosphere Safety Department, Kemerovo State University, Kemerovo, Russian Federation 